\title{
Electrocardiography findings and clinical presentation in Ebstein's anomaly
}

Mayank Dalakoti ${ }^{1}$, MBBS, MRCP, Devinder Singh ${ }^{1,2}$, MBBS, MRCP, Wee Tiong $\mathrm{Yeo}^{1,2}$, MBBS, MRCP, Lik Wui Edgar Tay ${ }^{1,2}$, MRCP, FACC, Kian Keong $\underline{\text { Poh }}^{1,2}$, FRCP, FACC

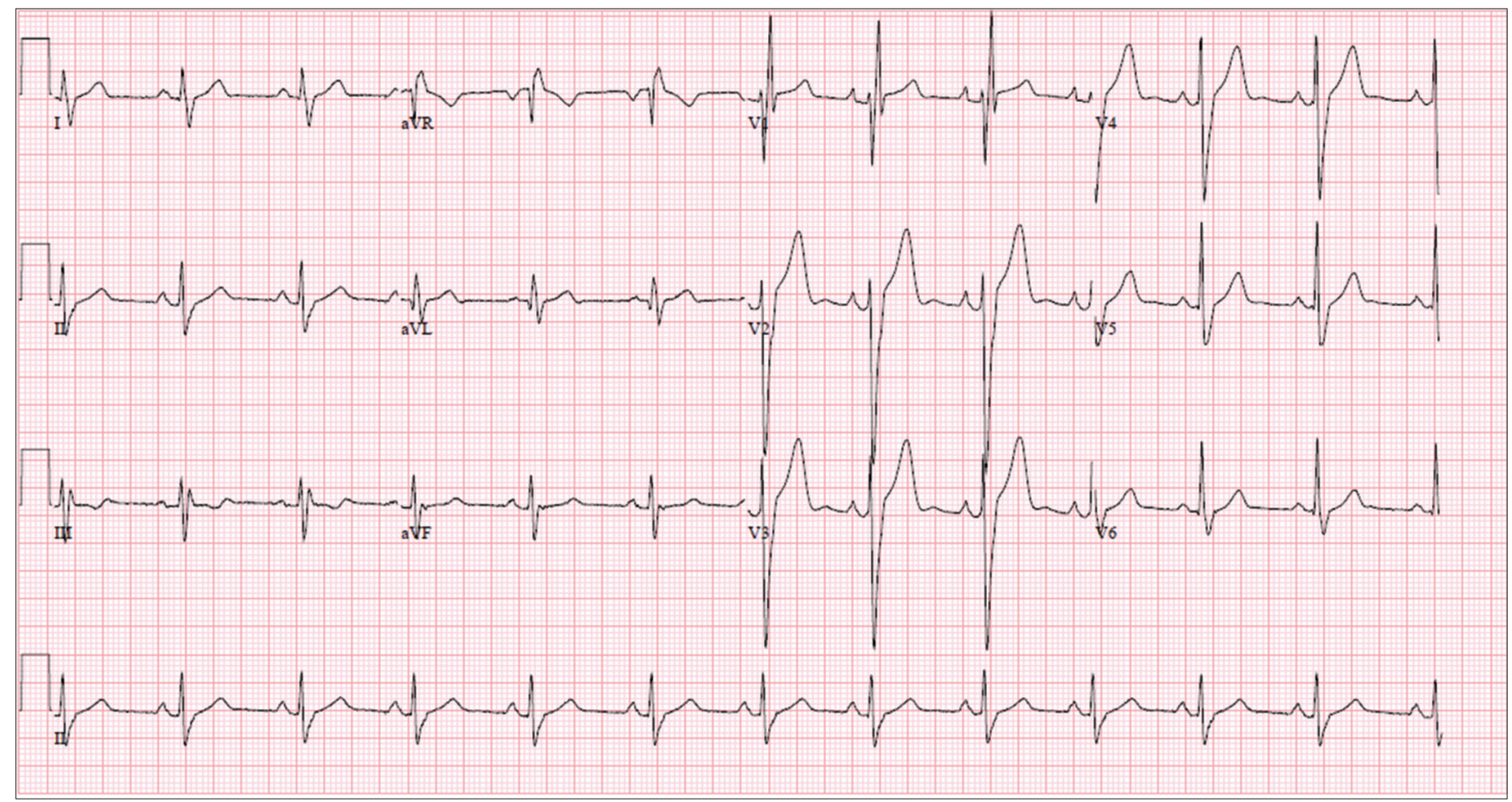

Fig. 1 ECG shows normal sinus rhythm with right bundle branch block.

\section{CASE 1}

\section{CLINICAL PRESENTATION}

A 26-year-old man with no past medical history presented with central chest discomfort of two weeks' duration. This was associated with reduced effort tolerance. The patient denied any palpitations, syncope, lower limb swelling or any family history of cardiac problems. On physical examination, he had a blood pressure of 120/80 mmHg and heart rate of 80 beats per minute (bpm). Auscultation of the precordium revealed a Grade 3 pan-systolic murmur that was loudest over the lower left sternal edge without radiation. The first and second heart sounds were normal. Lung sounds were clear and there was no pedal oedema. What does the electrocardiogram (ECG) in Fig. 1 show?

\section{ECG INTERPRETATION}

The ECG in Fig. 1 shows normal sinus rhythm at 80 bpm. P wave amplitude in lead V1 is $>1.5 \mathrm{~mm}$, suggestive of right atrial enlargement. There is an $\mathrm{rSR}^{\prime}$ pattern in $\mathrm{V} 1$, which is consistent with right ventricular conduction delay and suggestive of right bundle branch block (RBBB).

\section{CLINICAL COURSE}

Transthoracic echocardiography was performed. It showed a saillike tricuspid valve with apical displacement of the septal leaflet and atrialisation of the right ventricle (RV) with dilated right atrium (RA) and RV. There was trivial tricuspid regurgitation (TR). Left and right ventricular systolic function was preserved. The patient remained asymptomatic, and cardiac magnetic resonance (MR) imaging was scheduled to further assess the anomaly.

${ }^{1}$ Department of Cardiology, National University Heart Centre Singapore, ${ }^{2}$ NUS Yong Loo Lin School of Medicine, National University of Singapore, Singapore

Correspondence: Dr Mayank Dalakoti, Senior Resident, Department of Cardiology, National University Heart Centre Singapore, 5 Lower Kent Ridge Road, Singapore 119074. mayank_dalakoti@nuhs.edu.sg 


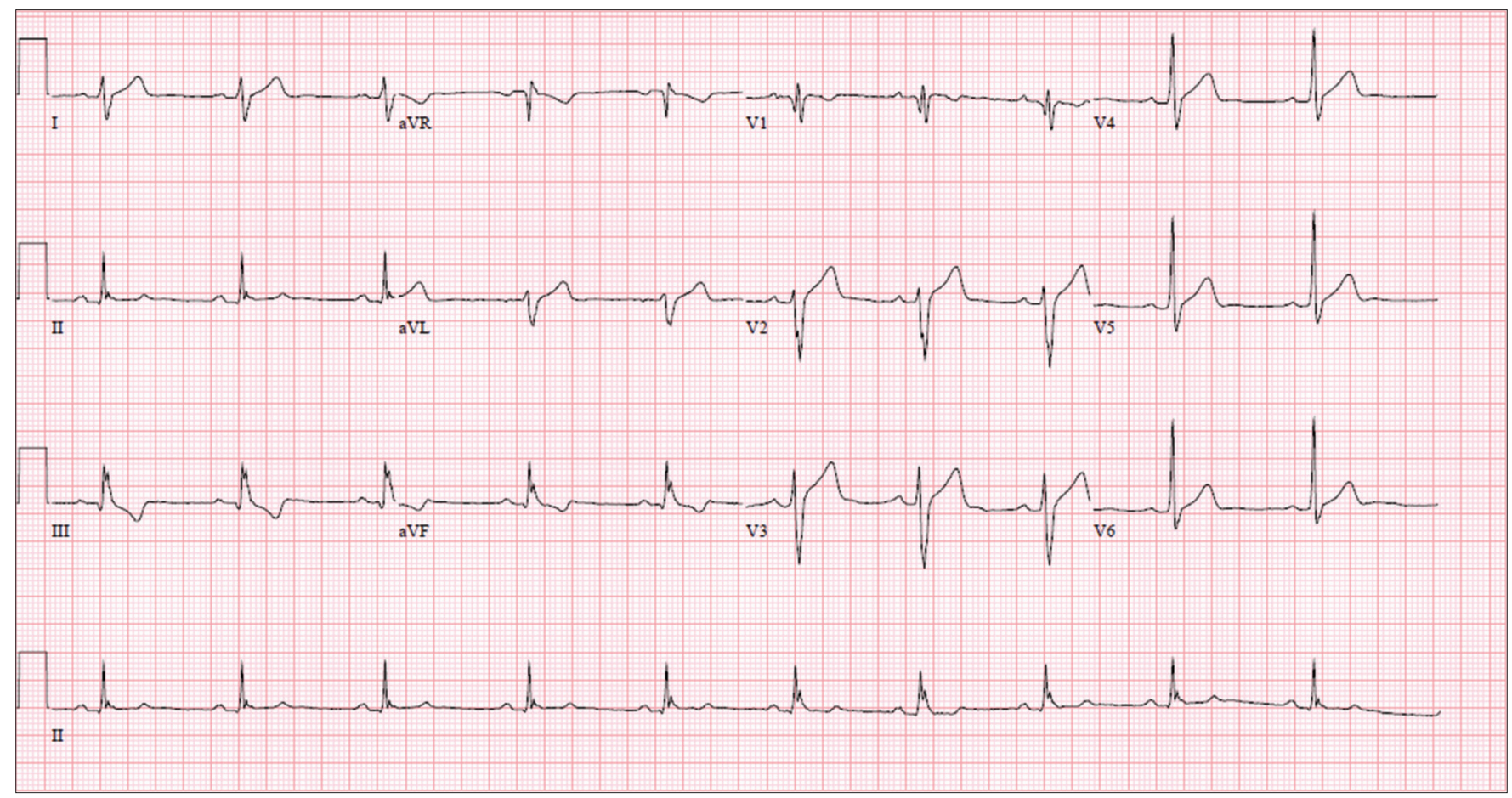

Fig. 2 ECG shows normal sinus rhythm and QRS fragmentation.

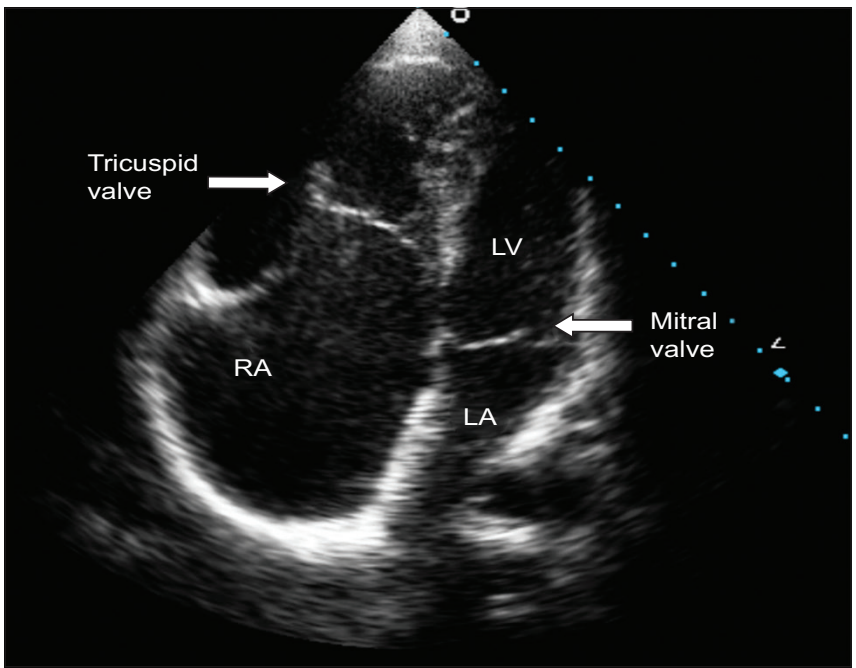

Fig. 3 Echocardiogram in apical four-chamber view shows significant apical displacement of the septal tricuspid leaflet with large RA and right ventricle. Note the sail-like appearance of the anterior tricuspid leaflet. LA: left atrium; LV: left ventricle; RA: right atrium

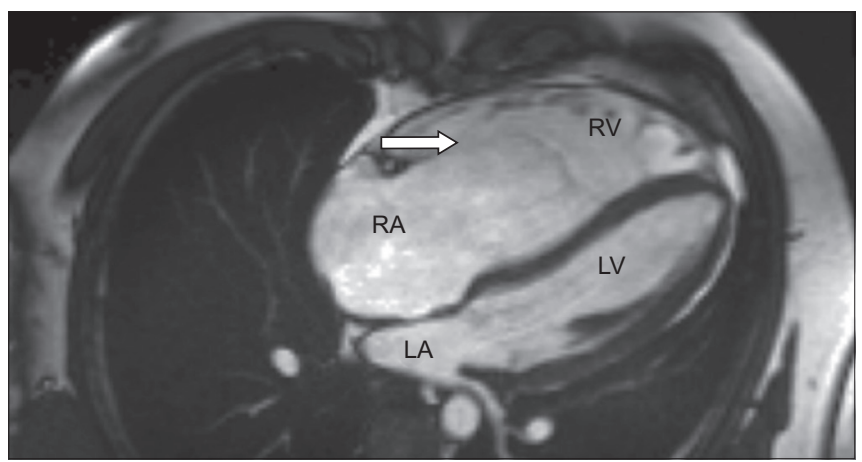

Fig. 4 Cardiac MR imaging in four-chamber view shows a significantly dilated RA with sail-like anterior tricuspid leaflet (arrow). There is apical displacement of the septal tricuspid leaflet. LA: left atrium; LV: left ventricle; $\mathrm{RA}$ : right atrium; RV: right ventricle

\section{CASE 2}

\section{CLINICAL PRESENTATION}

A 14-year-old boy with a history of Ebstein's anomaly was scheduled for a follow-up visit. He was otherwise well and denied any exertional symptoms. There was no chest pain, syncope, palpitations, orthopnoea or pedal oedema. The patient's blood pressure was 100/80 mmHg and heart rate was $65 \mathrm{bpm}$. Cardiac examination showed a 2/6 pan-systolic murmur over the lower left sternal edge. ECG was performed (Fig. 2).

\section{ECG INTERPRETATION}

The ECG in Fig. 2 shows sinus rhythm. There is an rsr' pattern in lead V1 with fragmentation of the QRS complex. This is consistent with an incomplete RBBB.

\section{CLINICAL COURSE}

Transthoracic echocardiogram showed significant apical displacement of the septal tricuspid leaflet with an enlarged RA and RV suggestive of Ebstein's anomaly (Fig. 3). There was normal left and right ventricular ejection fraction. The atrial septal device was stable with no evidence of any inter-atrial shunt. There was severe TR. Cardiac MR imaging was also performed (Fig. 4), showing a giant RA with severely dilated RV. There was normal RV systolic function and severe TR. The patient remained stable and on regular follow-up.

\section{CASE 3}

\section{CLINICAL PRESENTATION}

A 14-year-old girl who was previously followed up at another centre for cardiac abnormality was referred for recurrent palpitations. Her blood pressure was $110 / 70 \mathrm{mmHg}$ and heart rate was 80 bpm. Physical examination showed a well-thrived girl 


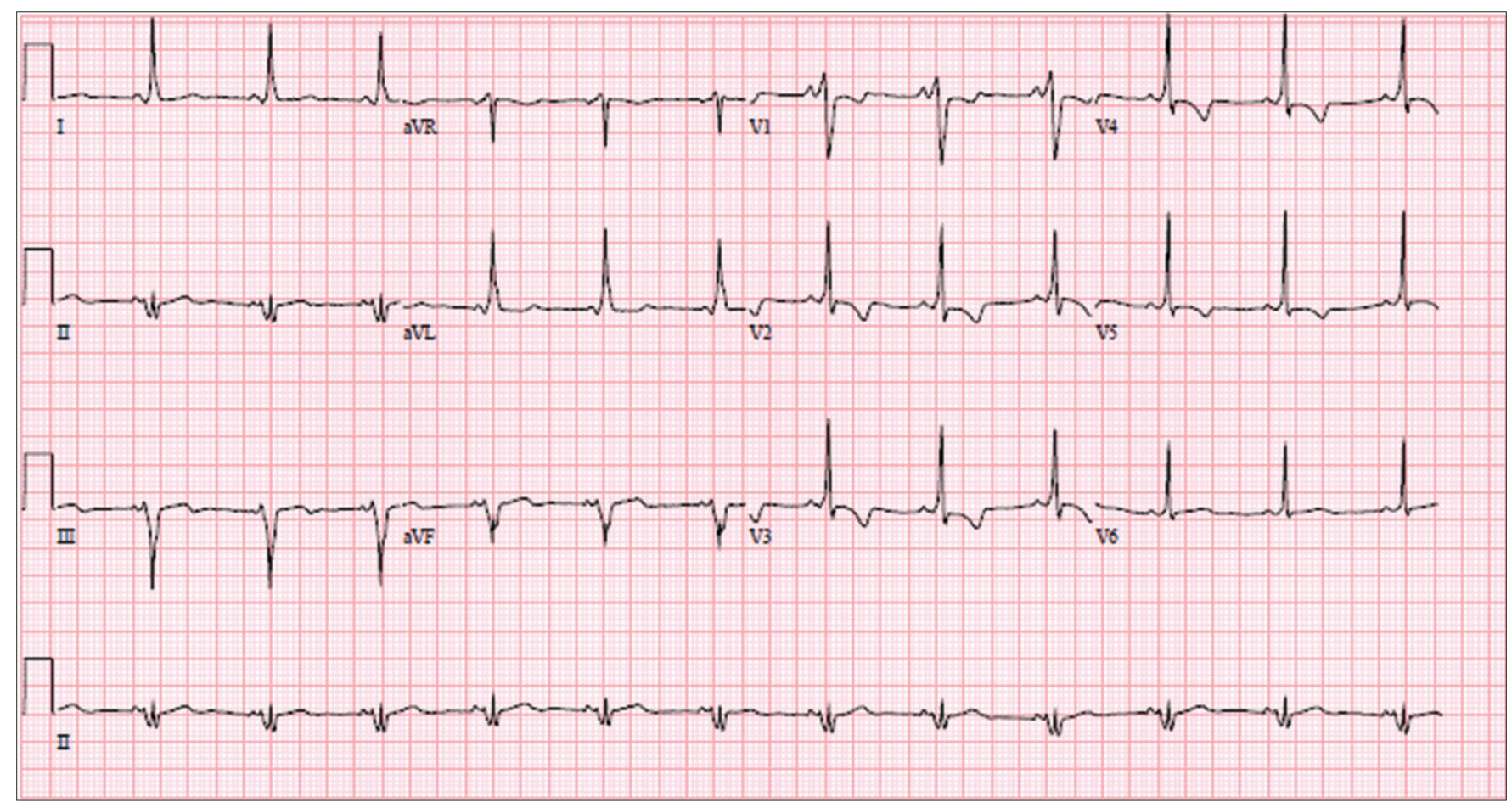

Fig. 5 ECG shows prominent delta waves consistent with Wolff-Parkinson-White syndrome.

without evidence of cyanosis. There was a Grade 3 pan-systolic murmur that was loudest over the left lower sternal edge without any radiation. ECG was performed (Fig. 5).

\section{ECG INTERPRETATION}

The ECG in Fig. 5 shows sinus rhythm at a rate of 75 bpm. The PR interval is short with slurring of the QRS complex upstroke, which is consistent with a delta wave. There is early transition in the precordial leads with tall $\mathrm{R}$ waves in $\mathrm{V} 2$ and $\mathrm{T}$-wave inversion in $\mathrm{V} 1-\mathrm{V} 5$. These findings are consistent with the ECG pattern of Wolff-Parkinson-White syndrome.

\section{CLINICAL COURSE}

Transthoracic echocardiography showed an Ebstsein's anomaly malformation involving the tricuspid valve. There was a sail-like anterior leaflet and apical displacement of the septal leaflet by $31 \mathrm{~mm} / \mathrm{m}^{2}$. There was non-coaptation of the tricuspid valve leaflets, resulting in severe TR. The RA and RV were dilated. Right and left ventricular ejection fraction was preserved. There was an associated secundum atrial septal defect.

The patient underwent an electrophysiology study that showed multiple right-sided accessory pathways. Successful radiofrequency ablation of multiple right-sided pathways was done. Subsequently, she successfully underwent a surgical cone repair of the tricuspid valve with bidirectional cavopulmonary connection.

\section{DISCUSSION}

Ebstein's anomaly occurs in approximately one per 200,000 live births and accounts for $<1 \%$ of cases of congenital heart disease. ${ }^{(1,2)}$ This anomaly was first described by Wilhelm
Ebstein in 1866 in a report titled 'Concerning a very rare case of insufficiency of the tricuspid valve caused by a congenital malformation'. (3) It is a congenital malformation characterised by malformed and displaced tricuspid valve leaflets that are partly attached to the tricuspid valve annulus and partly attached to the right ventricular endocardium. A wide range of tricuspid valve abnormalities are seen in Ebstein's anomaly, ranging from minimal displacement of the septal and inferior leaflets to severe displacement with tethering. Management of Ebstein's anomaly requires understanding of the anatomy and physiology along with clinical features. Although the diagnosis is largely based on echocardiographic features, ECG is an important tool.

\section{Anatomy}

The normal tricuspid valve has three leaflets: anterior, posterior and septal. In Ebstein's anomaly, the septal and posterior leaflets are adherent to the underlying myocardium. There is apical displacement of the tricuspid valve leaflets, leading to dilatation of the atrialised portion of the RV. The anterior leaflet may have fenestrations and redundancy. There is marked dilatation of the anatomic tricuspid valve annulus. This results in a large chamber separating the true annulus from the functional RV, which is referred to as the 'atrialised' portion of the RV. ${ }^{(4,5)}$

The embryological basis is the failure of delamination of the septal, inferior and anterior leaflets of the tricuspid valve from the right ventricular myocardium. ${ }^{(3)}$ Multiple cardiac defects are associated with Ebstein's anomaly, including atrial or ventricular septal defects, patent foramen ovale, patent ductus arteriosus and pulmonary outflow tract obstruction. ${ }^{(3)}$ Arrhythmias are common and include accessory pathways 
such as Wolff-Parkinson-White syndrome as well as atrial tachyarrhythmias. ${ }^{(6)}$

\section{Pathophysiology}

Reduced right heart contractility and presence of significant tricuspid regurgitation result in reduced forward flow of blood through the right heart. There is progressively severe dilatation of the RA and RV.

\section{Clinical features}

Clinical features are varied and depend largely on the anatomic severity. Most patients present in childhood, although a delayed presentation in adulthood can occur with less severe malformations. Neonates present with cyanosis and heart failure secondary to $T R$, while children and adults may present with features of cyanosis, heart failure, arrhythmias or paradoxical embolism. ${ }^{(7)}$ On physical examination, patients may have a right ventricular heave and a pan-systolic murmur from TR. The first heart sound is widely split, and the tricuspid component is loud and delayed because of closure of the large anterior leaflet. The $V$ wave of TR is seldom observed in the jugular pulse because of the damping effect of the large atrium, despite the presence of severe TR. ${ }^{(2)}$

\section{Diagnostic evaluation Electrocardiography}

The ECG can be a useful tool in the diagnosis of Ebstein's anomaly. Although ECG features may not be specific to the diagnosis, most patients with Ebstein's anomaly have an abnormal ECG. ${ }^{(2)}$ Characteristic ECG features in Ebstein's anomaly include tall $\mathrm{P}$ waves $(>2.5 \mathrm{~mm}$ ) in leads II and $\mathrm{V} 1$ due to right atrial enlargement. ${ }^{(7)}$ In some cases, giant 'Himalayan' $\mathrm{P}$ waves have been described, defined as height $>5 \mathrm{~mm} .{ }^{(8)}$ Our patient in Case 1 had ECG features suggestive of right atrial enlargement.

PR interval prolongation with first degree AV block can be seen in $42 \%$ of patients. ${ }^{(2)}$ This is attributed to prolonged conduction through an enlarged RA. Conversely, a short PR interval may be seen when associated with pre-excitation. ${ }^{(9)}$ Our patient in Case 3 had a short PR interval associated with delta waves due to pre-excitation.

The QRS complex may be prolonged in Ebstein's anomaly, due to prolonged activation of the RV. Incomplete or complete RBBB is seen in $44 \%$ of patients, ${ }^{(10)}$ as seen in all three ECG cases. This happens due to a delay in conduction through the specialised conduction tissues. ${ }^{(11)}$ Triphasic or tetraphasic QRS complexes can be observed. The QRS complex may be fragmented due to abnormal conduction through the atrialised RV, as was observed in all three cases. The finding of a giant $P$ wave together with an atypical RBBB in V1 is suggestive of Ebstein's anomaly. ${ }^{(10)}$ The amplitude of the $\mathrm{R}$ and $\mathrm{R}^{\prime}$ in $\mathrm{V} 1$ is smaller than those in $\mathrm{V} 5$ and $V 6$, contrary to a typical RBBB. Similarly, the presence of $q R$ pattern in V1 also suggests an enlarged atrialised RV. ${ }^{(12)}$

Arrhythmias are another characteristic feature. Pre-excitation occurs more commonly in Ebstein's anomaly than in any other congenital heart disease. Accessory pathways, when present, tend to be right-sided ones. Other arrhythmias in Ebstein's anomaly include paroxysmal atrial flutter, atrial fibrillation and ventricular tachycardia.

\section{Chest radiography}

Chest radiographs may be normal in mild cases. In severe cases, a large globular heart is seen with a narrow waist. The right atrial silhouette may be enlarged. The term 'box-shaped heart' is used to describe some cases. Pulmonary vasculature may be normal or reduced.

\section{Echocardiography}

Transthoracic echocardiography is the diagnostic modality of choice for Ebstein's anomaly. It is diagnosed based on apical displacement of the septal leaflet of the tricuspid valve by $8 \mathrm{~mm} / \mathrm{m}^{2}$ or greater, combined with an elongated sail-like appearance of the anterior leaflet. ${ }^{(2)}$ The atrium and atrialised portion of the RV are commonly markedly enlarged with significant TR. These features were found in all three cases described, some of which are shown in Fig. 3. The presence of associated cardiac defects, such as atrial septal defect, can be assessed by echocardiography. Three-dimensional echocardiography can provide useful information about tricuspid valve morphology, as the valve may not be seen well on conventional two-dimensional echocardiography.

\section{Cardiac magnetic resonance imaging}

Cardiac MR imaging offers further information into functional right ventricular volume and function, TR fraction and shunt quantification. It also allows for assessment of left ventricular size and function, left ventricular non-compaction, and regions of fibrosis on myocardial delayed enhancement imaging. The features of Ebstein's anomaly on cardiac MR imaging can be seen in Fig. 4.

\section{Treatment \\ Medical management}

Patients with Ebstein's anomaly should be routinely followed up by a cardiologist with expertise in congenital heart disease. Management includes assessment for cyanosis and heart failure. Asymptomatic patients can be carefully monitored. Patients who develop heart failure and are not candidates for surgery can be treated with standard heart failure therapy, including diuretics. Patients with a history of paradoxical embolism or atrial fibrillation should be anticoagulated with warfarin. However, newer anticoagulants have not been specifically studied in the Ebstsein's anomaly population. Options for management of arrhythmias include surgical or catheter ablation. Endocarditis prophylaxis before appropriate dental procedures should be considered in cyanotic Ebstein's anomaly patients or those with a prosthetic cardiac valve.

\section{Physical activity}

Exercise recommendations are based on the American College of Cardiology's Task Force I report on congenital heart disease. 
Patients with mild Ebstein's anomaly with nearly normal heart size and no arrhythmias can participate in all sports. Those with severe Ebstein's anomaly should not routinely participate in sports. ${ }^{(13)}$

\section{Arrhythmias}

Supraventricular arrhythmias are often seen in patients with Ebstein's anomaly. Patients with symptomatic arrhythmias or those scheduled for surgical repair should undergo an electrophysiology study. The success rate for catheter ablation is lower in patients with Ebstein's anomaly compared to those with structurally normal hearts. ${ }^{(14)}$ Surgical interruption can be performed if catheter ablation is unsuccessful or inappropriate.

\section{Surgery}

Indications for surgery include symptoms such as decreasing exercise capacity, clinical features of cyanosis, paradoxical embolism, congestive cardiac failure and progressive RV dilation or reduction of RV systolic function. ${ }^{(15)}$ Surgical techniques should be tailored to each patient, in discussion with a multidisciplinary team. Aims of surgery include improving the severity of TR, reducing the arrhythmia burden, closing any inter-atrial communications and pacemaker placement when necessary. ${ }^{(15)}$ When possible, tricuspid valve repair is the preferred surgical method. Tricuspid valve replacement is reserved for valves not amenable to repair, or in patients with massive RV or tricuspid annular dilatation. Options for tricuspid valve replacement include mechanical or bioprosthetic valves. Operative management includes anti-arrhythmia procedures such as maze and ablation of accessory pathways.

\section{Summary}

Ebstein's anomaly is a complex congenital condition with variable presentations. Recognition of clinical and ECG features can lead to improved diagnosis and management.

ABSTRACT Ebstein's anomaly is a congenital malformation characterised by tricuspid valve pathology with right heart enlargement. Cases of Ebstein's anomaly can vary widely in severity, anatomy and presentation. In this article, we presented three cases of Ebstein's anomaly and discussed the presentation as well as electrocardiographic (ECG) changes. Patients may first present to their primary care physicians with cardiac symptoms such as reduced effort tolerance together with an abnormal ECG. ECG changes suggestive of right heart enlargement are important in the initial consideration and eventual formal diagnosis of the condition.

Keywords: arrhythmias, cardiac, Ebstein's anomaly, electrocardiography, tricuspid valve

\section{REFERENCES}

1. Hoffman JI, Kaplan S. The incidence of congenital heart disease. J Am Coll Cardiol 2002; 39:1890-900

2. Attenhofer Jost $\mathrm{CH}$, Connolly HM, Dearani JA, Edwards WD, Danielson GK. Ebstein's anomaly. Circulation 2007; 115:277-85.

3. van Son JA, Konstantinov IE, Zimmermann V. Wilhelm Ebstein and Ebstein's malformation. Eur J Cardiothorac Surg 2001; 20:1082-5.

4. Barbara DW, Edwards WD, Connolly HM, Dearani JA. Surgical pathology of 104 tricuspid valves (2000-2005) with classic right-sided Ebstein's malformation. Cardiovasc Pathol 2008; 17:166-71.

5. Martinez RM, O'Leary PW, Anderson RH. Anatomy and echocardiography of the normal and abnormal tricuspid valve. Cardiol Young 2006; 16 Suppl 3:4-11.

6. Reich JD, Auld D, Hulse E, Sullivan K, Campbell R. The Pediatric Radiofrequency Ablation Registry's experience with Ebstein's anomaly. Pediatric Electrophysiology Society. J Cardiovasc Electrophysiol 1998; 9:1370-7.

7. Warnes CA, Williams RG, Bashore TM, et al. ACC/AHA 2008 guidelines for the management of adults with congenital heart disease: a report of the American College of Cardiology/American Heart Association Task Force on Practice Guidelines (Writing Committee to Develop Guidelines on the Management of Adults With Congenital Heart Disease). Developed in Collaboration With the American Society of Echocardiography, Heart Rhythm Society, International Society for Adult Congenital Heart Disease, Society for Cardiovascular Angiography and Interventions, and Society of Thoracic Surgeons. J Am Coll Cardiol 2008; 52:e143-e263.

8. Kaushik ML, Sharma M, Kashyap R. 'Himalayan' p wave. J Assoc Physicians India 2007; 55:856

9. Soo WM, Chong E, Teo SG, Poh KK. ECG delta waves in patients with palpitation. Singapore Med J 2011; 52:68-72.

10. Pérez-riera AR, Barbosa-Barros R, Daminello-Raimundo R, de Abreu LC, Nikus K. Electro-vectorcardiographic and electrophysiological aspects of Ebstein's anomaly. Ann Noninvasive Electrocardiol 2018; 24:e12590.

11. Ayyachamy SS, Teo SG, Tay EL, Yip JW, Poh KK. ECGs of structural heart disease: Part 2. Singapore Med I 2012; 53:77-81.

12. Sodi-Pallares D, Bisteni A, Herrmann GR. Some views on the significance of $q R$ and QR type complexes in right precordial leads in the absence of myocardial infarction. Am Heart J 1952; 43:716-34.

13. Graham TP Jr, Bricker JT, James FW, Strong WB. 26th Bethesda Conference: recommendations for determining eligibility for competition in athletes with cardiovascular abnormalities. Task Force 1: congenital heart disease. Med Sci Sports Exerc 1994; 26(10 Suppl):S246-53.

14. Hebe J. Ebstein's anomaly in adults. Arrhythmias: diagnosis and therapeutic approach. Thorac Cardiovasc Surg 2000; 48:214-9.

15. Dearani JA, Danielson GK. Surgical management of Ebstein's anomaly in the adult. Semin Thorac Cardiovasc Surg 2005; 17:148-54. 


\section{SINGAPORE MEDICAL COUNCIL CATEGORY 3B CME PROGRAMME} (Code SMJ 201911A)

Question 1. Ebstein's anomaly is associated with:
(a) Mitral valve prolapse.
(b) Patent foramen ovale.
(c) Aortic valve stenosis.
(d) Pulmonary stenosis.

Question 2. The following ECG changes are associated with Ebstein's anomaly:
(a) QRS fragmentation.
(b) Left ventricular hypertrophy.
(c) Right bundle branch block.
(d) Right atrial enlargement.

Question 3. The following arrhythmias are associated with Ebstein's anomaly:
(a) Brugada syndrome.
(b) Wolff-Parkinson-White syndrome.
(c) Atrial fibrillation.
(d) Ventricular tachycardia.

Question 4. The following are considered indications for surgical intervention in Ebstein's anomaly:
(a) Severe pulmonary hypertension.
(b) Cyanosis.
(c) Paradoxical embolism.
(d) Congestive cardiac failure.

Question 5. Which of the following are expected physical examination findings in a patient with Ebstein's anomaly?
(a) Pan-systolic murmur.
(b) Widely split first heart sound.
(c) Giant V wave.
(d) Right ventricular heave.

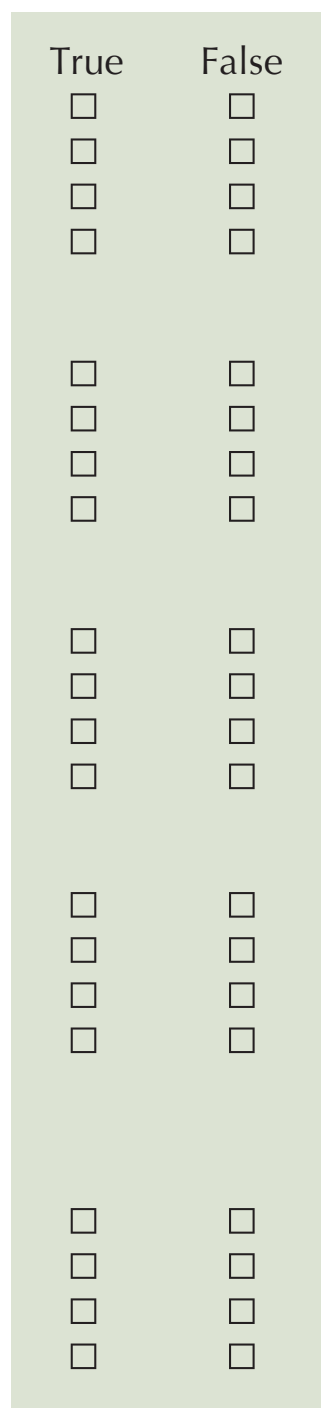

\section{Doctor's particulars:}

Name in full:

Specialty:

MCR no.:

Email:

\section{SUBMISSION INSTRUCTIONS:}

Visit the SMJ website: http://www.smj.org.sg/current-issue and select the appropriate quiz. You will be redirected to the SMA login page.

For SMA member: (1) Log in with your username and password (if you do not know your password, please click on 'Forgot your password?'). (2) Select your answers for each quiz and click 'Submit'.

For non-SMA member: (1) Create an SMJ CME account, or log in with your SMJ CME username and password (for returning users). (2) Make payment of SGD 21.40 (inclusive of $7 \%$ GST) via PayPal to access this month's quizzes. (3) Select your answers for each quiz and click 'Submit'.

RESULTS:

(1) Answers will be published online in the SMJ January 2020 issue. (2) The MCR numbers of successful candidates will be posted online at the SMJ website by 7 January 2020. (3) Passing mark is $60 \%$. No mark will be deducted for incorrect answers. (4) The SMJ editorial office will submit the list of successful candidates to the Singapore Medical Council. (5) One CME point is awarded for successful candidates. (6) SMC credits CME points according to the month of publication of the CME article (i.e. points awarded for a quiz published in the December 2017 issue will be credited for the month of December 2017, even if the deadline is in January 2018).

Deadline for submission: (November 2019 SMJ 3B CME programme): 12 noon, 31 December 2019. 